\title{
Foreword celebrating the career of Professor Satoshi Ōmura
}

\author{
The Journal of Antibiotics (2017) 70, 455-456; doi:10.1038/ja.2017.25
}

A s Editor-in-Chief, I am delighted that this special edition of The Journal of Antibiotics is being published in honor of Professor Satoshi Ōmura, Distinguished Emeritus Professor at Kitasato University in Japan and Emeritus Editor-in-Chief of this Journal. This exceptional issue has been produced in recognition of his brilliant research achievements, the impact of the many life-enhancing products that have arisen from his work, his considerable accomplishments in the field of both scientific endeavor and innovation and for his roles in promoting education and the mentoring of young scientists. Plus, of course, we cannot overlook his invaluable contributions to the development and improvement of this Journal for more than 50 years, including the 499 papers that he has published in our pages so far. Professor Ōmura has been an editorial board member since 1973. He served as an Editor-in-Chief from 2005 and was appointed as an Editor-in-Chief Emeritus in 2014. This plan is also to mark our sincere appreciation of his longstanding support to this Journal.

I am also extremely pleased to report that this singular edition received numerous submissions from researchers active in the field of antibiotics and related bioactive products, all of whom expressed a heartfelt desire to help celebrate Professor Ōmura's achievements, and I know that their contributions will help make the issue truly memorable.

Satoshi Ōmura is, highly respectful of Japanese traditions and acutely cognizant of the benefits that nature can provide, who went on to make a truly global impact, one of the growing number of Nobel Prize winners emanating from Japan. He is a symbol of the worldleading excellent scientific research, which was being widely carried out throughout Japan in the last half of the twentieth century. He was born in 1935 in Nirasaki City, Yamanashi, Japan, and graduated in 1958 from the University of Yamanashi before taking his first steps on what has been a worldwide quest to seek and dispense knowledge and insight while simultaneously promoting a communal and humanitarian approach in all aspects of scientific research and collaborative partnerships. Having moved to Tokyo and after developing a predilection for chemistry, he earned a Master's degree in 1963 from the Tokyo University of Science, followed by a $\mathrm{PhD}$ degree in pharmaceutical sciences in 1968 from the University of Tokyo, followed by another in chemistry in 1970 from the Tokyo University of Science. Subsequently, he returned to his family roots in Yamanashi and began what would prove to be a long and highly successful research career, his first position being as a research associate at the Yamanashi University (1963-1965). In 1965, his world began to expand again and he began his career-long association with Tokyo's world-renowned Kitasato Institute, initially as a Researcher, over the years occupying various posts, culminating in his appointment in 1990 to the position of President. During this time, he was fortunate to undertake research work overseas and establish pioneering research collaborations, as well as become well versed and highly experienced as an administrator and fund-raiser, helping to drive forward substantial improvements in the scope and status of the institute, which facilitated a merger between the Kitasato Institute and Kitasato University. He served as a Professor in the Graduate School of Infection Control Sciences, Kitasato University (2001-2007), followed by his current position as Professor Emeritus and Special Coordinator of a Research Project for Drug Discovery from Natural Products, Kitasato Institute for Life Sciences, as well as being appointed as a Distinguished Emeritus Professor at the university. Because of the success of his research work at Wesleyan University in the United States and the connections he made there in the early 1970s, and the immeasurably successful interdisciplinary, international collaborations which he initiated, he was appointed as the inaugural Max Tishler Professor of Chemistry at Wesleyan University in 2005, a post he held until 2016, when he was elevated to Emeritus Professor so that a younger generation could provide new vision and help shape the future directions of the department.

As an indication of Ōmura's standing internationally, Nobel Prize winning chemist Professor EJ Corey calls him simply a 'Giant', a straightforward indicator of his breakthrough results in the field of natural products chemistry and medicinal chemistry.

Ōmura's discoveries in such fields have been recognized by his peers and ordinary people around the world. His profound contributions impressively span the areas of microbiology, organic chemistry, biomedicine, compound isolation and structural elucidation, biosynthesis, biological analysis, chemical synthesis, animal health and human health. His results are described in over 1000 publications and many books and patents in his own name. Some of the chemical compounds he has discovered are named in the titles of about 1200 research papers every year, showing that his work has not been restricted to just himself but that many others have used and benefited from his success to carry out their own work, some of which has been recognized with Nobel Prizes for the researchers concerned.

Over a 50-year career, he has discovered over 180 distinct types and almost 500 novel bioactive compounds, many playing significant roles in medicine, agriculture, industry or as important reagents, including 
staurosporine and lactacystin. However, so far, the most extraordinary and most significant of his discoveries has been the avermectins.

Avermectin and its dihydro derivative, ivermectin, are among the best health-improving chemical compounds ever found, comparable to such chemicals as penicillin and aspirin. Ivermectin, in particular, has been used extensively for human, and animal health as the world's leading anthelmintic agent, as well as for agricultural purposes and to treat parasitic skin diseases. Hundreds of millions of mainly poor people living in communities throughout the tropics have been saved from blindness and grotesque disfiguration by this drug and millions more are expected to benefit from it as its' uses expand into new domains, such as strongyloidiasis and scabies, while its true potential remains, as yet, relatively undiscovered. The World Health Organization is currently overseeing global disease elimination programs for Onchocerciasis and Lymphatic filariasis, primarily using ivermectin, with both operations close to accomplishing their goal of elimination by 2020 .

The full list of natural products discovered in Ōmura's laboratories is extremely impressive, as is his pioneering work to create unheralded, highly innovative 'hybrid' antibiotics through genetic manipulation. The overall inspirational aspect of his work cannot be underestimated, for it fuels the field of chemical synthesis with opportunities to discover and invent further concepts and novel products in chemistry, biology and medicine.

Ōmura's extraordinary contributions to natural products chemistry have been repeatedly recognized internationally, as indicated by his many awards and honors, for example, the Charles Thom Award (Society for Industrial Microbiology (USA)), Robert Koch Gold Medal (Germany), Prince Mahidol Award (Thailand), Nakanishi Prize (Japan Chemical Society and American Chemical Society), Ernest Guenther Award in Chemistry of Natural Products (American Chemical Society), Hamao Umezawa Memorial Award (International Society of Chemotherapy), Japan Academy Prize, Tetrahedron Prize for Creativity in Organic Chemistry, Arima Award (International Union of Microbiology), Person of Cultural Merit (Japan), Norman R. Farnsworth ASP Research Achievement Award and Canada's Gairdner Global Health Award. He has been elected as a member of the Japan Academy, Deutsche Akademie der Naturforscher, Leopoldina, and European Academy of Sciences. He is also a foreign associate of the US National Academy of Sciences, the Institut de France Academie des Sciences and the Chinese Academy of Engineering. His honorary memberships include those of the American Society of Biochemistry and Molecular Biology, the Royal Society of Chemistry (UK), Japanese Society of Bacteriology, Chemical Society of Japan, the Society for Actinomycetes and the Society of Biochemistry, Biotechnology and Agrochemistry of Japan. In 2007, he was awarded the l'Ordre National de la Legion d'honneur (Chevalier).

Above all, the 2015 Nobel Prize in Physiology or Medicine, which he was awarded for his work in the discovery of ivermectin, exemplifies the entirety of his huge contributions to science. Unquestionably, the influence and impact of Ōmura, who constantly claims that he is 'just an Organic Chemist' extends beyond the field of chemistry and antibiotics and into the worlds of science, health and social development, where the impact of his results have had-and are having - an immeasurably beneficial impact in improving the lives and welfare of hundreds of millions of people in communities and societies around the globe. His story should also serve as an inspiration to us all-especially to motivate aspiring young scientists everywheresomething which would give Satoshi Ōmura himself great contentment.

Kuniaki Tatsuta
Editor-in-Chief
Distinguished Fellow and Professor Emeritus
Waseda University, Tokyo, Japan
E-mail: tatsuta@waseda.jp

Kuniaki Tatsuta ef Waseda University, Tokyo, Japan E-mail:tatsuta@waseda.jp 